\title{
Glucagon-Like Peptide-1 Analogues Exenatide and Liraglutide Exert Inhibitory Effect on the Early Phase of Liver Regeneration After Partial Hepatectomy in Rats
}

\author{
J. FONTANA ${ }^{1}$, O. KUČERA ${ }^{2}$, V. MEZERA ${ }^{2}$, M. ANDĚL ${ }^{1}$, Z. ČERVINKOVÁ ${ }^{2}$ \\ ${ }^{1}$ Centre for Research on Diabetes, Metabolism and Nutrition, Third Faculty of Medicine, Charles \\ University in Prague, Prague, Czech Republic, ${ }^{2}$ Department of Physiology, Faculty of Medicine in \\ Hradec Králové, Charles University in Prague, Hradec Králové, Czech Republic
}

Received August 11, 2016

Accepted February 21, 2017

On-line July 18, 2017

\section{Summary}

Glucagon-like peptide-1 (GLP-1) is an incretin known for proliferative and antiapoptotic effects on various tissues. Exenatide and Liraglutide are GLP-1 analogues used in clinical practice as antidiabetic drugs. Since GLP-1 and its analogues exert significant effect on liver metabolism and since changes in intermediary metabolism play an important role in the process of liver regeneration, we decided to determine the effect of Exenatide and Liraglutide on the early phase of liver regeneration and selected metabolic parameters in a model of $2 / 3$ partial hepatectomy $(\mathrm{PHx})$ in rats. Animals were submitted either to $\mathrm{PHx}$ or laparotomy and received 3 doses of either GLP-1 analogues (Exenatide $-42 \mu \mathrm{g} / \mathrm{kg}$ b.w., Liraglutide $-0.75 \mathrm{mg} / \mathrm{kg}$ b.w.) or saline intraperitoneally. We analyzed body and liver weight, liver bromodeoxyuridine incorporation, liver content of DNA, triacylglycerols and cholesterol and biochemical serum parameters. Bromodeoxyuridine labeling was significantly lower in hepatectomized rats receiving either type of GLP-1 analogues when compared to hepatectomized controls. This effect was more pronounced in the Liraglutide group compared to Exenatide $(p<0.001)$. In addition, liver DNA content was lower in hepatectomized rats receiving Liraglutide than in hepatectomized control rats $(p<0.001)$. In conclusion, GLP-1 analogues Exenatide and Liraglutide significantly inhibited an early phase of liver regeneration after $\mathrm{PHx}$ in rats. This inhibitory effect was more pronounced in rats receiving Liraglutide.

\section{Key words}

GLP-1 • Exenatide • Liraglutide • Liver regeneration • Partial hepatectomy

\section{Corresponding author}

J. Fontana, Centre for Research on Diabetes, Metabolism and Nutrition, Third Faculty of Medicine, Charles University in Prague, Ruská 87, 10000 Prague, Czech Republic. E-mail: josef.fontana@lf3.cuni.cz

\section{Introduction}

Glucagon-like peptide-1 (GLP-1) is a peptide hormone derived from the proglucagon gene. Its biologically active forms in plasma, GLP-1 (7-36) amide and GLP-1 (7-37), contain 30 (31) amino acids. GLP-1 belongs to the incretin family, together with the gastric inhibitory polypeptide (GIP, also known as the glucosedependent insulinotropic peptide) (Holst 2007, Baggio and Drucker 2007). These hormones as a part of the entero-insular axis increase postprandial insulin release, accounting for approximately $50-70 \%$ of postprandial insulin secretion (Nauck et al. 1986, Baggio and Drucker 2007). The major source of GLP-1 in man are the intestinal endocrine L-cells that are present mainly in the ileum and colon (Eissele et al. 1992). GLP-1 has a short biological half-life in the circulation (1-2 $\mathrm{min})$, because it is effectively degraded by ubiquitous enzyme dipeptidyl peptidase 4 (DPP4) (Vilsboll et al. 2003). Products of the cleavage, GLP-1 (9-36) amide or GLP-1 (9-37), are inactive as the insulin secretagogues, but could have some other effects in the body (e.g. on liver cells, heart or blood vessels) (Holst 2007, Ban et al. 2008, Tomas et al. 2010). For example, GLP-1 (9-36) amide was reported to 
reduce gluconeogenesis and inhibit fatty acid oxidation in the liver (Tomas et al. 2010). Analogues of GLP-1 resistant to degradation action of DPP4 are used in clinical practice as antidiabetic drugs. Currently two analogues, Exenatide (Ex4) and Liraglutide (LIRA), are commonly available (Russell-Jones and Gough 2012). Clinical trials have demonstrated that both analogues are attractive therapies for the treatment of type 2 diabetes, offering effective glycemic control (considerable reductions in $\mathrm{HbAlc}$ ) with a low risk of hypoglycemia (Russell-Jones and Gough 2012).

Pancreatic GLP-1 receptor is a G-protein coupled receptor, member of a secretin receptor family (Mayo et al. 2003). The receptor is expressed in various tissues including islets of Langerhans, central nervous system, cardiovascular system, lungs, kidneys, gastrointestinal tract and afferent vagal nerve endings (Mayo et al. 2003, Holst 2007). GLP-1 binding to the receptor leads to a wide range of effects, chiefly to a suppression of hepatic glucose production and modulation of lipid metabolism (Alcantara et al. 1997, Ding et al. 2006, Holst 2007, Baggio and Drucker 2007). Whether GLP-1 effects on hepatocytes are mediated through pancreatic type of GLP-1 receptor, is still unclear due to ambiguous results of existing studies (Tomas et al. 2010, Samson and Bajaj 2013). However, it is evident that GLP-1 affects liver functions and liver metabolism, mainly metabolism of lipids and saccharides (Alcantara et al. 1997, Ding et al. 2006).

Disruption of liver lipid metabolism affects the pace of the liver regeneration since TAG and free fatty acids (FFA) serve as main energy substrates for proliferating liver cells in the early period after partial hepatectomy (Bucher 1963, Šimek and Sedláček 1965, Shteyer et al. 2004, Fernandez et al. 2006, Rudnick and Davidson 2012). GLP-1 and its analogues were described to modulate gene expression of key proteins of lipid metabolism in the liver and to change the liver lipid content (Ding et al. 2006, Ben-Shlomo et al. 2011, Sharma et al. 2011, Lee et al. 2012, Mells et al. 2012). Therefore, we hypothesized that GLP-1 signaling could interfere with the process of liver regeneration. Only few studies assessed effect of GLP-1 and/or its analogues on proliferation and apoptosis of hepatocytes in vitro (Aviv et al. 2009, Sharma et al. 2011). To our best knowledge, there are no studies evaluating the effect of GLP-1 analogues on liver regeneration induced by partial hepatectomy.

Despite the increasing rate of usage and importance of both GLP-1 analogues as antidiabetic drugs and previously described modulation of liver functions and liver lipid metabolism by their action (supported by proliferative and antiapoptotic effects of GLP-1 on various tissues, e.g. pancreatic $\beta$-cells) (Farilla et al. 2002), data regarding their potential effect on liver regeneration are missing in literature. Therefore, in our present work, we evaluated the effect of GLP-1 analogues Exenatide and Liraglutide on the early phase of liver regeneration and selected metabolic parameters after $2 / 3$ partial hepatectomy $(\mathrm{PHx})$ in male Wistar rats (Higgins and Anderson 1931). Remaining hepatocytes progress through the cell cycle in a relatively synchronous manner during the first 1-2 days (Fausto et al. 2006, Michalopoulos 2007, Hanse et al. 2009). This is why we have chosen an early interval after PHx.

\section{Methods}

\section{Chemicals}

Liraglutide was purchased from Bachem AG (Bubendorf, Switzerland), Exenatide from Cederlane (Burlington, Ontario, Canada). Primary mouse anti-BrdU monoclonal antibody was obtained from DAKO (Glostrup, Denmark), biotinylated anti-mouse secondary antibody from Jackson ImmunoResearch Laboratories (West Grove, PA, USA), streptavidin conjugate of peroxidase from DAKO (Glostrup, Denmark). 3,3'-diaminobenzidine-tetrahydrochloride, bromodeoxyuridine and other chemicals were obtained from Sigma-Aldrich (Madison, WI, USA).

\section{Animals and experimental design}

Experiments were performed on male Wistar rats (BioTest, Konarovice, Czech Republic) with initial body weight $264 \pm 17 \mathrm{~g}$, age 8 weeks. The animals were housed at $22 \pm 1{ }^{\circ} \mathrm{C}, 55 \pm 10 \%$ humidity, $12 \mathrm{~h}$ light/dark cycles, air exchange 12-14 times/h and had a free access to standard laboratory pelleted diet (ST-1, Velaz, Czech Republic) and to tap water. All work with animals followed the European Guidelines on Laboratory Animal Care and animals received care according to the guidelines set out by the Animal-Welfare Body of the Faculty of Medicine in Hradec Králové and by the Committee for Protection of Experimental Animals of the Third Faculty of Medicine, Charles University in Prague, Czech Republic. Both committees approved our experiment. All planned experiments were in agreement with law No. 246/1992 (for protection of animals against 
cruelty) and notice No. 419/2012 (the protection of animals for experimental purposes).

The animals were divided into following six groups, for each group $n=6$ :

Group I - LAP-S (laparotomy + saline)

Group II - LAP-Ex4 (laparotomy + Exenatide $42 \mu \mathrm{g} / \mathrm{kg}$ body weight)

Group III - LAP-LIRA (laparotomy + Liraglutide $0.75 \mathrm{mg} / \mathrm{kg}$ b.w.)

Group IV - PHx-S (PHx + saline)

Group V - PHx-Ex4 (PHx + Exenatide $42 \mu \mathrm{g} / \mathrm{kg}$ b.w.)

Group VI - PHx-LIRA (PHx + Liraglutide $0.75 \mathrm{mg} / \mathrm{kg}$ b.w.)

Animals were submitted to $2 / 3$ partial hepatectomy or sham operation - laparotomy (LAP) under ether anaesthesia. They received 3 doses of either GLP-1 analogues (Ex4 - $42 \mu \mathrm{g} / \mathrm{kg}$ b.w., LIRA -
$0.75 \mathrm{mg} / \mathrm{kg}$ b.w., dissolved in saline (S)) or equivalent amount of saline in the total volume of $1 \mathrm{ml} / 100 \mathrm{~g} \mathrm{~b} . \mathrm{w}$. intraperitoneally. Doses of GLP-1 analogues used in our work were chosen based on literature data (Koehler et al. 2009, Bjerre Knudsen et al. 2010, Vrang et al. 2012, Patel et al. 2014). The first dose was injected $24 \mathrm{~h}$ before the surgery, the second dose $12 \mathrm{~h}$ before the surgery and the third dose immediately after the surgery. Bromodeoxyuridine (BrdU - $100 \mathrm{mg} / \mathrm{kg}$ b.w.) was administered intraperitoneally $23 \mathrm{~h}$ after the surgery. The animals were sacrificed one hour after the BrdU application (i.e. $24 \mathrm{~h}$ after the surgery) by exsanguination from abdominal aorta in ether anesthesia. Liver and serum samples were collected. Samples for subsequent evaluation were immediately frozen in liquid nitrogen and stored at $-80{ }^{\circ} \mathrm{C}$ until further analysis. The liver lobes excised during partial hepatectomy and the liver remnants were weighed. Scheme of a study protocol is shown in Fig. 1.

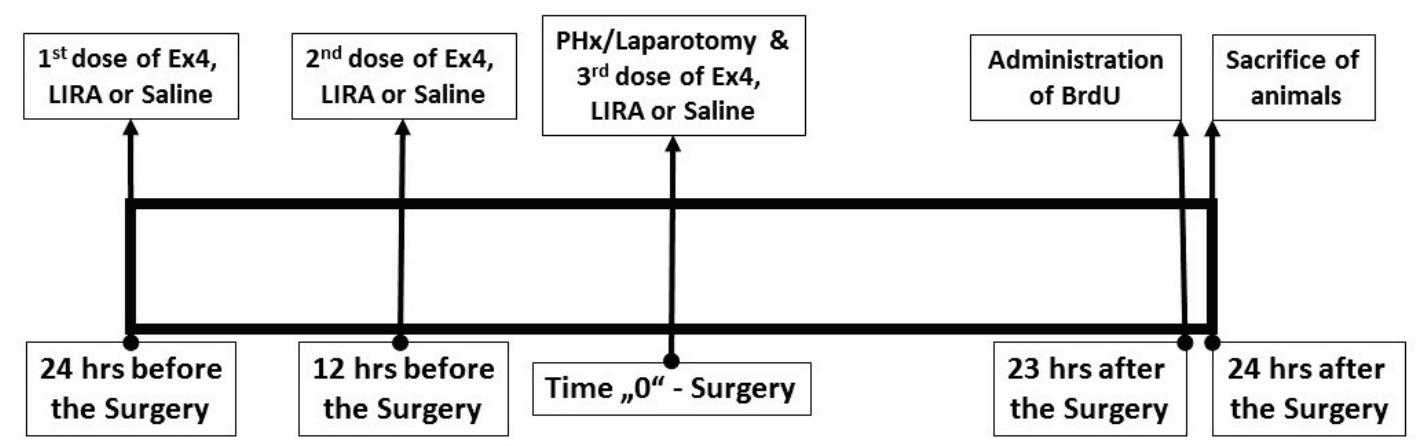

Fig. 1. Scheme of a study protocol.

Microscopic analysis - incorporation of bromodeoxyuridine in the Liver

BrdU staining and its quantification was described previously (Bader et al. 2011). Briefly, after the animals had been sacrificed, liver samples were fixed in $4 \%$ neutral formaldehyde. Paraffin sections were incubated with primary mouse anti-BrdU monoclonal antibody, subsequently with biotinylated anti-mouse secondary antibody and then with a streptavidin conjugate of peroxidase. Visualization of bound antibody was performed by 3,3'-diaminobenzidine tetrahydrochloride and hydrogen peroxide. Quantification of BrdU incorporation was performed by counting of BrdUpositive hepatocyte nuclei in nine representative microscope fields in each section (objective magnification 10x) using an Olympus IX51 microscope and subsequently quantified by a computer-aided image analysis system NIS-Elements AR 2.30 (Nikon, Lewisville, TX, USA).

\section{Liver content of DNA, triacylglycerols and cholesterol}

Liver content of DNA was assessed using the Quant-iT ${ }^{\mathrm{TM}}$ PicoGreen ${ }^{\circledR}$ dsDNA Assay Kit (Life Technologies, USA) in accordance with manufacturer's instructions. Briefly, samples of liver tissue were lysed in lysis buffer (RIPA) supplemented by proteinase $\mathrm{K}$ (Qiagen, Germany). The liver samples lysates were pipetted into a 96-wellplate in duplicates and subsequently incubated at room temperature, protected from light for $5 \mathrm{~min}$ with the prepared PicoGreen solution. Plates were excited at $480 \mathrm{~nm}$ and the fluorescence emission intensity was measured at $520 \mathrm{~nm}$ using spectrophotometer TECAN Infinite M200 (Tecan Group AG, Switzerland). Fluorescence intensity was 
plotted against DNA concentration.

Lipid extraction from rat livers was carried out by chloroform-methanol extraction (Bligh and Dyer 1959). Total cholesterol and triacylglycerols (TAG) were subsequently assessed using commercial kits (Roche Diagnostics GmbH, Mannheim, Germany).

\section{Serum biochemical analysis}

Serum concentrations of urea, creatinine, total bilirubin, glucose, total cholesterol and TAG, serum activities of alanine aminotransferase (ALT), aspartate aminotransferase (AST) and alkaline phosphatase (ALP) were performed in the Department of Clinical Biochemistry and Diagnostics, University Hospital Hradec Králové. All measurements were determined by standard biochemical methods using an automatic analyzer P800 Modular (Roche).

\section{Determination of tissue proteins}

Protein content was determined by the method of Bradford (Bradford 1976) using bovine serum albumin as a standard.

\section{Statistical analysis}

Results are expressed as the mean \pm SD. GraphPad Prism 4.03 software (Graph Pad Software, San Diego, CA, USA) was used for statistical analysis. Kolmogorov-Smirnov test was used for proving the normality. In the case of normal distribution, ANOVA followed by Tukey-Kramer's post hoc test was used for group comparison. In non-Gaussian distribution, non-parametric Kruskal-Wallis tests and Dunn's post hoc test were used. Statistical significance was set at $\mathrm{p}<0.05$.

\section{Results}

Animals, body and liver weight

During the whole experiment all animals survived until the sacrifice. No animal had any complications. In group I (LAP-S), the body weight rose between day 1 and day $2 \quad(\mathrm{p}<0.05)$. There was a significant decline in body weight in hepatectomized animals: group IV (PHx-S) day 2 versus day $3(\mathrm{p}<0.001)$, group V (PHx-Ex4) day 1 versus day3 $(\mathrm{p}<0.001)$ and group VI (PHx-LIRA) day 2 versus day $3(\mathrm{p}<0.01)$. In addition, there were nonsignificant trends to decline in body weight after laparotomy from day 2 to day 3 . Group IV (PHx-S) and group V (PHx-Ex4) had lower body weights on day 3 than their respective laparotomized controls $(\mathrm{p}<0.01, \mathrm{p}<0.05$, respectively) (Table 1).

Neither the relative weight of the excised liver, nor the relative weight of liver remnant in hepatectomized groups showed any significant differences (Table 1).

Table 1. Percentual body weight of animals and relative liver weight during the experiment.

\begin{tabular}{|c|c|c|c|c|c|}
\hline & $\begin{array}{l}\text { Body weight } \\
\text { - Day } 1 \text { - } \\
24 \text { h before } \\
\text { surgery }\end{array}$ & $\begin{array}{c}\text { Body weight } \\
\text { - Day } 2 \text { - } \\
\text { day of surgery }\end{array}$ & $\begin{array}{c}\text { Body weight } \\
\text { - Day } 3 \text { - } \\
24 \text { h after surgery }\end{array}$ & $\begin{array}{l}\text { Weight of } \\
\text { excised liver } \\
\text { (g/kg b.w.) } \\
\text { - Day } 2 \text { - }\end{array}$ & $\begin{array}{c}\text { Liver remnant } \\
\text { weight (g/kg } \\
\text { b.w.) } \\
\text { - Day } 3 \text { - }\end{array}$ \\
\hline$L A P-S$ & $100.0 \pm 7.5 \%$ & $111.7 \pm 2.4 \% *$ & $103.4 \pm 1.4 \%$ & & \\
\hline$L A P-E x 4$ & $100.0 \pm 4.9 \%$ & $102.0 \pm 4.9 \%$ & $95.7 \pm 1.6 \%$ & & \\
\hline$L A P-L I R A$ & $100.0 \pm 2.1 \%$ & $102.0 \pm 8.0 \%$ & $93.8 \pm 2.2 \%$ & & \\
\hline$P H x-S$ & $100.0 \pm 4.9 \%$ & $104.7 \pm 6.9 \%$ & $89.8 \pm 6.3 \% \dagger \dagger \dagger,+\dagger$ & $34.4 \pm 1.2$ & $18.1 \pm 1.0$ \\
\hline$P H x-E x 4$ & $100.0 \pm 5.4 \%$ & $94.9 \pm 5.6 \%$ & $84.6 \pm 3.2 \% * * *, t$ & $32.4 \pm 0.9$ & $16.5 \pm 1.0$ \\
\hline$P H x-L I R A$ & $100.0 \pm 5.0 \%$ & $103.6 \pm 9.2 \%$ & $90.3 \pm 2.3 \% \dagger \dagger$ & $33.1 \pm 3.4$ & $18.5 \pm 1.1$ \\
\hline
\end{tabular}

Day $1=100 \%$, calculated as an average weight of animals in the group. $* p<0.05, * * * p<0.001$ vs. Day $1 ;++p<0.01,+\dagger+p<0.001$ vs. Day $2 ; \neq p<0.05, \neq \neq p<0.01$ vs. corresponding laparotomized groups.

Incorporation of bromodeoxyuridine in liver and liver content of DNA

Immunohistochemical BrdU staining, marker of
S-phase activity (Tanaka et al. 2011), provided only sporadic BrdU-positive nuclei in the laparotomized groups (group I, II and III) and did not exert any 
significant differences among these groups. In the hepatectomized groups (group IV, V and VI), the BrdU-positive nuclei were highly positive, significantly higher than in the respective laparotomized controls $(p<0.001)$. Treatment with either of the analogues resulted in lower BrdU labelling when compared to saline controls in the hepatectomized groups $(p<0.001$ for both comparisons). LIRA compared to Ex4 caused even lower BrdU labeling $(\mathrm{p}<0.001)$ (Fig. 2). In the hepatectomized groups treated with GLP-1 analogues, BrdU-positive nuclei and thus the synthesis of DNA and liver regeneration were located mostly in the periportal regions, centrilobular areas showed only rare BrdUpositivity (Fig. 3a-3d).
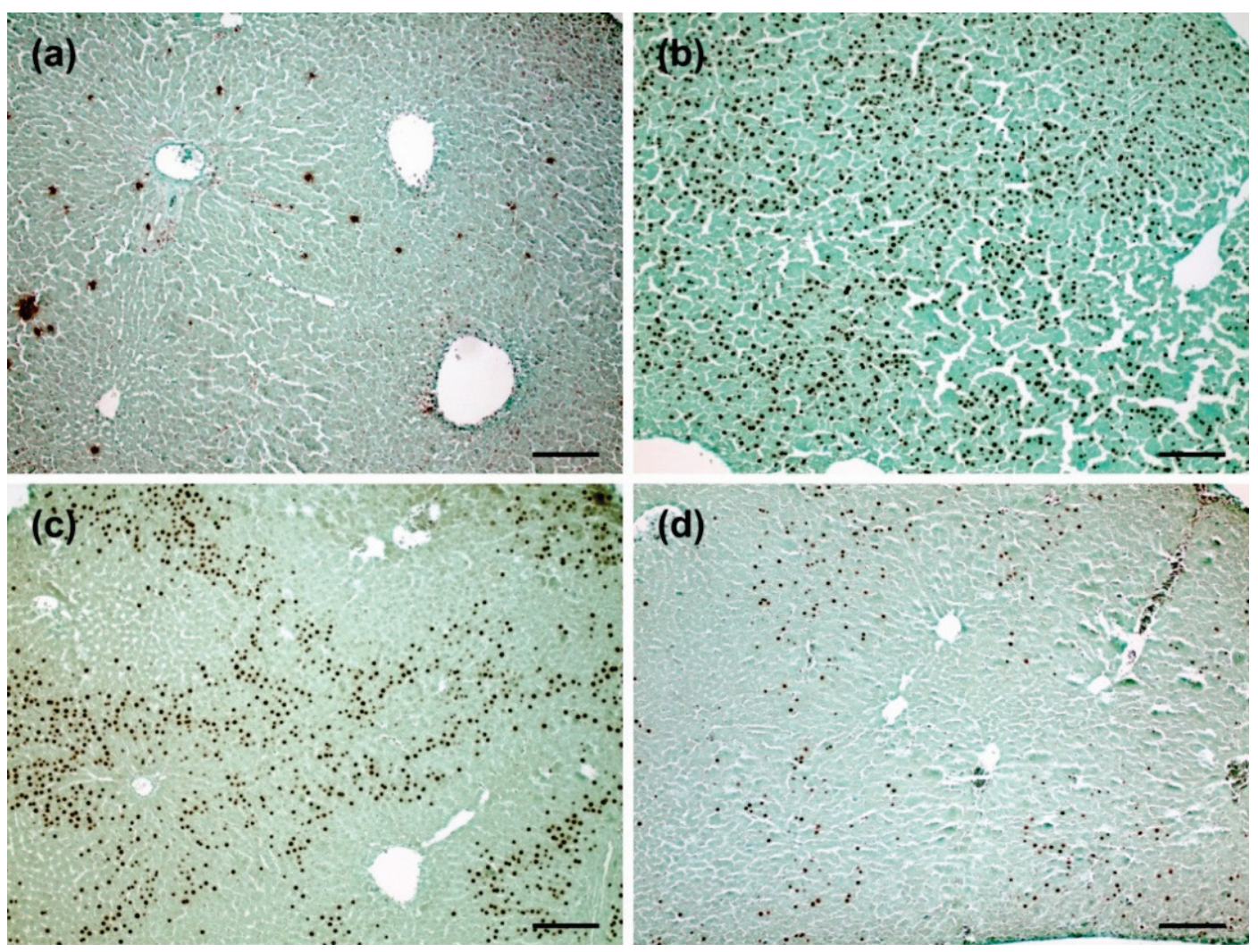

Fig. 3. Immunohistochemistry of BrdU incorporation in the liver $24 \mathrm{~h}$ after the surgery. Representative microphotographs of histological samples from: (a) rats after laparotomy with saline (LAP-S), (b) rats after $\mathrm{PHx}$ with saline (PHx-S), (c) rats after PHx with Exenatide (PHx-Ex4) and (d) rats after PHx with Liraglutide (PHx-LIRA). In the laparotomized groups (3a) only sporadic BrdU-positive nuclei; in the hepatectomized groups ( $3 b, 3 c$ and $3 d$ ) numerous BrdU-positive nuclei, groups treated with GLP-1 analogues (3c and 3d) show lower density of BrdU-positive cells when compared to control animals (3b), Liraglutide treatment caused more pronounced difference. Note that the BrdU-positive nuclei are located mostly in the periportal regions; centrilobular areas show only rare BrdU-positivity. (Objective magnification $\times 10$, bar $100 \mu \mathrm{m}$ ).

Liver content of DNA reflected results of BrdU staining. Hepatectomized animals treated with Liraglutide showed significantly lower liver DNA content when compared to those treated with saline $(\mathrm{p}<0.001)$ and Ex4

\section{Bromodeoxyuridine incorporation in liver}

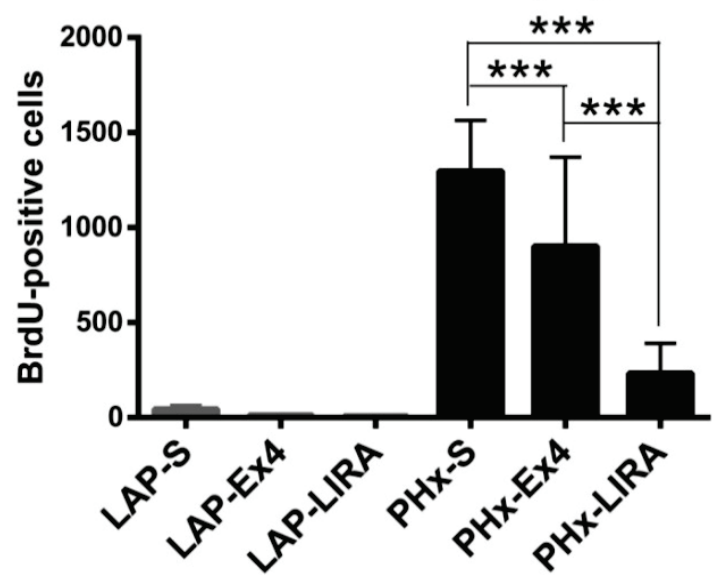

Fig. 2. Number of BrdU-stained cells in the liver $24 \mathrm{~h}$ after the surgery $(* * * p<0.001)$. 


\section{DNA content in liver $24 \mathrm{hrs}$ after surgery}

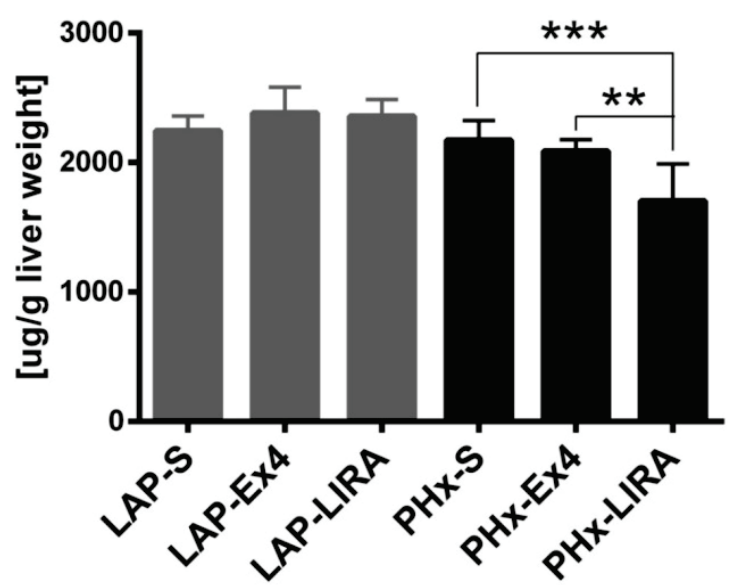

Fig. 4. Liver content of DNA $24 \mathrm{~h}$ after the surgery $(* * p<0.01$, $* * * p<0.001$, respectively).
Liver content of triacylglycerols and cholesterol

Liver content of TAG was higher in all hepatectomized groups when compared to respective laparotomized groups, $(\mathrm{p}<0.001$ for all comparisons). Neither of the analogues had any significant effect on the liver content of triacylglycerols. There was only a trend to lower TAG content in analogues-treated animals than in saline-treated controls; this nonsignificant trend was present in both laparotomized and hepatectomized animals.

Hepatectomized animals had higher cholesterol content than their respective laparotomized controls; this difference was significant only in saline-treated animals $(p<0.01)$. Liraglutide treatment in hepatectomized animals resulted in lower cholesterol content than treatment with saline $(\mathrm{p}<0.05)$ (Table 2).

Table 2. Liver content of triacylglycerols and cholesterol.

\begin{tabular}{|c|c|c|c|c|c|c|}
\hline & LAP-S & LAP-Ex4 & LAP-LIRA & PHx-S & PHx-Ex4 & PHx-LIRA \\
\hline $\begin{array}{l}\text { Liver TAG } \\
(\mathrm{mmol} / \mathrm{l})\end{array}$ & $0.580 \pm 0.090$ & $0.480 \pm 0.050$ & $0.490 \pm 0.090$ & $1.970 \pm 0.280^{* * *}$ & $1.730 \pm 0.330^{* * *}$ & $1.690 \pm 0.580^{* * *}$ \\
\hline $\begin{array}{l}\text { Liver cholesterol } \\
(\mathrm{mmol} / \mathrm{l})\end{array}$ & $0.307 \pm 0.028$ & $0.340 \pm 0.054$ & $0.278 \pm 0.040$ & $0.407 \pm 0.020 * *$ & $0.382 \pm 0.046$ & $0.323 \pm 0.049 \dagger$ \\
\hline
\end{tabular}

$* * p<0.01, * * * p<0.001$ vs. corresponding laparotomized groups; $+p<0.05$ vs. saline animals after the same surgery.

\section{Serum biochemical parameters}

As depicted in Table 3, Liraglutide treatment led to a higher serum urea level than either saline or Exenatide treatment after any surgery (LAP-LIRA vs. LAP-S: $p<0.001$; LAP-LIRA vs. LAP-Ex4: $p<0.001$; PHx-LIRA vs. PHx-S: $p<0.05$; PHx-LIRA vs. PHx-Ex4: $\mathrm{p}<0.01$ ). Exenatide did not affect serum urea levels. Neither of analogues had any effect on serum creatinine level.

Serum total bilirubin was higher in the hepatectomized groups when compared to the respective laparotomized groups; this difference was significant when comparing the LAP-S group with $\mathrm{PHx}-\mathrm{S}$ group $(\mathrm{p}<0.001)$ and LAP-Ex4 group with PHx-Ex4 group $(\mathrm{p}<0.01)$. In hepatectomized animals, Liraglutide administration led to significantly lower levels of serum total bilirubin than the administration of saline $(\mathrm{p}<0.05)$.

Hepatectomized animals treated with Liraglutide (PHx-LIRA) showed lower glycemia than corresponding laparotomized controls (LAP-LIRA) $(\mathrm{p}<0.001)$. Similar but nonsignificant trends were observed when comparing saline or Exenatide treated hepatectomized animals with their laparotomized controls. Serum glycemia was higher after Liraglutide administration than after saline or Exenatide administration in the laparotomized groups $(\mathrm{p}<0.001, \mathrm{p}<0.01$, respectively).

All hepatectomized animals showed significantly lower levels of serum cholesterol than their respective laparotomized controls $(p<0.001$ for saline groups, $\mathrm{p}<0.001$ for Ex4 groups, $\mathrm{p}<0.01$ for LIRA groups). Both analogues led to slightly lower serum TAG concentration than saline; however, a significant difference was observed only when comparing Liraglutide and saline treatment in hepatectomized animals $(\mathrm{p}<0.001)$.

Hepatectomized groups showed higher serum activities of ALT, AST and ALP when compared to respective laparotomized groups. GLP-1 analogues showed nonsignificant trends to lower ALT (Ex4), AST (Ex4) and ALP (both Ex4, LIRA) than saline in animals after PHx (Table 3). 
Table 3. Serum biochemical parameters.

\begin{tabular}{|c|c|c|c|c|c|c|}
\hline & LAP-S & LAP-Ex4 & LAP-LIRA & PHx-S & PHx-Ex4 & PHx-LIRA \\
\hline Urea (mmol/l) & $6.43 \pm 1.02$ & $5.88 \pm 0.64$ & $11.45 \pm 3.51^{\dagger \dagger}$, & $6.53 \pm 0.60$ & $6.15 \pm 1.31$ & $9.98 \pm 1.54^{\dagger}, \#$ \\
\hline $\begin{array}{l}\text { Creatinine } \\
(\mu \mathrm{mol} / \mathrm{l})\end{array}$ & $23.0 \pm 3.20$ & $24.2 \pm 2.90$ & $27.3 \pm 6.10$ & $22.5 \pm 1.60$ & $21.3 \pm 2.30$ & $25.2 \pm 5.10$ \\
\hline $\begin{array}{l}\text { Total bilirubin } \\
(\mu \mathrm{mol} / \mathrm{l})\end{array}$ & $2.02 \pm 0.15$ & $1.98 \pm 0.18$ & $1.88 \pm 0.12$ & $4.17 \pm 0.99 * * *$ & $3.55 \pm 0.91 * *$ & $2.82 \pm 0.78^{\dagger}$ \\
\hline $\begin{array}{l}\text { Glycemia } \\
\text { (mmol/l) }\end{array}$ & $7.01 \pm 0.61$ & $7.51 \pm 0.92$ & $9.68 \pm 1.25^{\dagger \dagger}$ & $5.99 \pm 0.49$ & $6.91 \pm 0.68$ & $7.23 \pm 0.77 * * *$ \\
\hline $\begin{array}{l}\text { Cholesterol } \\
\text { (mmol/l) }\end{array}$ & $1.92 \pm 0.30$ & $2.21 \pm 0.34$ & $1.81 \pm 0.30$ & $1.19 \pm 0.28^{* * *}$ & $1.16 \pm 0.17 * * *$ & $1.14 \pm 0.17 * *$ \\
\hline$T A G(\mathrm{mmol} / \mathrm{l})$ & $0.64 \pm 0.17$ & $0.41 \pm 0.07$ & $0.58 \pm 0.12$ & $0.85 \pm 0.24$ & $0.59 \pm 0.15$ & $0.38 \pm 0.05^{\dagger \dagger \dagger}$ \\
\hline$A L T(\mu \mathrm{kat} / \mathrm{l})$ & $0.79 \pm 0.23$ & $1.14 \pm 0.45$ & $0.65 \pm 0.12$ & $1.69 \pm 0.51^{* *}$ & $1.34 \pm 0.27$ & $1.49 \pm 0.26^{* *}$ \\
\hline$A S T(\mu k a t / l)$ & $2.39 \pm 0.20$ & $2.82 \pm 1.23$ & $2.58 \pm 0.53$ & $5.30 \pm 1.94 * *$ & $4.59 \pm 0.93$ & $5.30 \pm 1.48^{*}$ \\
\hline ALP ( $\mu \mathrm{kat} / \mathrm{l})$ & $2.40 \pm 0.45$ & $2.19 \pm 0.27$ & $2.26 \pm 0.66$ & $5.79 \pm 1.61^{* * *}$ & $4.62 \pm 0.30^{* *}$ & $4.56 \pm 1.09^{* *}$ \\
\hline
\end{tabular}

$* p<0.05, * * p<0.01, * * * p<0.001$ vs. corresponding laparotomized groups; $+p<0.05,+\dagger+p<0.001$ vs. saline animals after the same surgery; $\neq \neq p<0.01, \neq \neq \neq p<0.001$ vs. Exenatide groups after the same surgery.

\section{Discussion}

GLP-1 analogues, Exenatide and Liraglutide are widely used in clinical practice as drugs for the treatment of type 2 diabetes. There are several in vitro and in vivo studies performed on various experimental animal models describing effects of GLP-1 and its analogues on liver lipid metabolism (Ding et al. 2006, Ben-Shlomo et al. 2011, Sharma et al. 2011, Lee et al. 2012, Mells et al. 2012). It was described previously that modulation of liver lipid metabolism affects process of liver regeneration since TAG and FFA are preferentially utilized as energy substrates in regenerating liver cells (Bucher 1963, Šimek and Sedláček 1965, Shteyer et al. 2004, Fernandez et al. 2006, Rudnick and Davidson 2012). Concurrently, only few studies evaluated effect of GLP-1 and its analogues on proliferation and apoptosis of hepatocytes in vitro (Aviv et al. 2009, Sharma et al. 2011) and to our best knowledge, there are no studies assessing the effect of GLP-1 analogues on liver regeneration induced by $\mathrm{PHx}$. Based on these facts, we decided to elucidate the effect of GLP-1 analogues, Exenatide and Liraglutide on the early phase of liver regeneration and selected metabolic parameters after $\mathrm{PHx}$ in Wistar rats in the present study.

We described that both GLP-1 analogues when compared to saline controls led to lower BrdU labeling in the hepatectomized groups. BrdU-positive nuclei and thus the synthesis of DNA and liver regeneration were located mostly in the periportal regions, centrilobular areas showed only rare BrdU-positivity. This zonal arrangement is typical for liver regeneration after $\mathrm{PHx}$, because hepatocyte proliferation progresses from periportal to centrilobular regions of the liver lobule (Grisham 1962, Michalopoulos 2007). As clearly seen in the microphotographs, GLP-1 analogues showed even more pronounced zonal distribution of proliferating hepatocytes. The inhibitory effect of Liraglutide was more pronounced than that of Exenatide in hepatectomized animals: there were even significant differences between Exenatide and Liraglutide treatment with regard to BrdU labeling and liver DNA content. The effect of Exenatide on liver DNA concentration in remnant liver displayed only nonsignificant difference from that of saline. Laparotomized groups did not exert any significant differences either in BrdU staining or in liver DNA content. Bromodeoxyuridine staining serves as a marker of S-phase activity indicating the number of cells synthesizing new DNA (Tanaka et al. 2011). The first peak of DNA synthesis in rat liver occurs approximately $24 \mathrm{~h}$ after the $\mathrm{PHx}$ and measurement of liver DNA content in this moment serves as an indicator of liver ability to regenerate (Bucher 1963, Fabrikant 1968, Kar et al. 2004, Fausto et al. 2006, Michalopoulos 2007). The first peak of mitoses in rat liver after the PHx is postponed, occurs approximately 29-33 h after the PHx (Bucher 1963, Weinbren and Taghizadeh 1965, Fabrikant 1968) and was not examined in the present study. 
Contrary to our expectations, hepatocytes did not respond to GLP-1 analogues by stimulation of proliferation, at least not during the early phase of liver regeneration after the PHx.

One of potential mechanisms, which could explain our results, is a modulation of processes concerning TAG metabolism in hepatocytes by GLP-1 action. TAG and FFA serve as main energy substrates for liver cells proliferating after PHx in the early postoperative period (Šimek and Sedláček 1965). GLP-1, its analogues and DPP4 inhibition were described to effectively modulate gene expression of key proteins of lipid metabolism in the liver and to change the liver lipid content (Ding et al. 2006, Ben-Shlomo et al. 2011, Sharma et al. 2011, Lee et al. 2012, Mells et al. 2012, Ben-Shlomo et al. 2013). Accumulation of TAG in liver cells after PHx is a standard finding (Bucher 1963, Shteyer et al. 2004, Michalopoulos 2007) and is necessary for the proper pace of liver regeneration (Bucher 1963, Shteyer et al. 2004). GLP-1 signaling could interfere with this crucial process, thereby GLP-1 analogues could provide less favorable conditions for liver regeneration. In our study, we assessed two parameters directly concerning TAG metabolism: liver TAG content and serum TAG level. Liver TAG content was higher in all hepatectomized groups than in respective laparotomized groups, which is in accord with other authors (Bucher 1963, Shteyer et al. 2004, Michalopoulos 2007). Both analogues showed non-significant trends to a decrease in liver TAG content in hepatectomized groups, which corresponds with previous studies (Ding et al. 2006, Ben-Shlomo et al. 2011, Sharma et al. 2011, Lee et al. 2012, Mells et al. 2012). Accordingly, suppressed liver TAG accumulation led to impaired liver regeneration after PHx (Shteyer et al. 2004, Fernandez et al. 2006, Rudnick and Davidson 2012). In account of serum TAG concentration in hepatectomized animals, only Liraglutide treatment led to lower levels than saline. A decline in serum TAG concentration after Liraglutide administration was described previously (Mells et al. 2012).

The accumulation of TAG in liver after the PHx could be explained by an increased lipomobilization in peripheral tissues induced by PHx-linked stress conditions and by higher rates of hepatic lipogenesis (Schofield et al. 1987, Tijburg et al. 1991, Kaibori et al. 1997, Fernandez et al. 2006). Reduced total capacity of remnant liver tissue to handle with serum free fatty acids and TAG and to effectively export them also participates in the rise of liver TAG (Delahunty and Rubinstein 1970, Tijburg et al. 1991). Several works described decrease in an excessive liver TAG and FFA accumulation after action of GLP-1, its analogues and DPP4 inhibition (Ding et al. 2006, Ben-Shlomo et al. 2011, Sharma et al. 2011, Lee et al. 2012, Mells et al. 2012). The effect is linked to an acceleration of expression of genes responsible for removal of lipids from hepatocytes (VLDL secretion), namely microsomal triglyceride transfer protein and ApoB (Mells et al. 2012).

Decline in serum cholesterol level in animals after PHx, already described in previous works could be explained by reduced synthetic capacity in hepatectomized liver and by increased cholesterol consumption during the regenerative process (Sekas and Cook 1979, Kaibori et al. 1997). An increase of liver cholesterol content in hepatectomized animals treated with saline in contrast to laparotomized control animals is a standard finding; stored cholesterol is used for formation of new cell membranes (Fernandez et al. 2006).

The elevated concentration of urea in Liraglutide treated groups with regard to the physiological concentration of creatinine was probably not caused by renal injury. This specific effect of Liraglutide could potentially be explained by increased utilization of amino acids, which can become alternative energy substrates when TAG utilization is attenuated (Rigotti et al. 1986, Holeček 1999). Indeed, the low liver TAG content and TAG plasma levels after GLP-1 analogue treatment observed in this study can be viewed as a state of disrupted hepatic lipid metabolism when its correct function is critically required. When the utilization of FFA is disrupted, hepatocytes begin to look for other suitable energy substrates, e.g. glucose (Fernandez et al. 2006) or amino acids, whose utilization is associated with an acceleration of urea cycle due to an increased ammonia production that needs to be detoxified to urea (Felig 1975, Brosnan 2003). This could also explain our findings of high serum urea levels after Liraglutide treatment.

Rise in serum activities of ALT, AST and ALP after partial hepatectomy is a well-described finding associated with a liver insult caused by PHx (Sekas and Cook 1979, Kaibori et al. 1997). This was also observed in the present study. Both GLP-1 analogues showed somewhat lower activities of these enzymes after PHx than saline, especially Exenatide. This may suggest a mild protection against liver damage. However, these positive effects do not reach statistical significance. The decline of the markers of liver damage after GLP-1 
analogues administration and/or in DPP4 inhibition was described in literature previously (Ben-Shlomo et al. 2011, Mells et al. 2012, Ben-Shlomo et al. 2013).

Elevated serum level of total bilirubin after PHx, which was found in the present study, is a standard finding described previously (Sekas and Cook 1979). Lower serum total bilirubin in hepatectomized animals after Liraglutide treatment than after saline treatment (supported by a mild trend to lower serum ALP activity) indicate that Liraglutide could possess some modulatory effects on bile flow. A positive effect of DPP4 inhibition on bile secretory function has been already described (Ben-Shlomo et al. 2013).

Among the key players regulating the processes of liver regeneration after the $\mathrm{PHx}$ are tissue inflammatory cytokines, namely $\mathrm{TNF} \alpha$ and IL-6 (Akerman et al. 1992, Cressman et al. 1996, Fausto et al. 2006, Michalopoulos 2007). In the case of their absence, the liver regeneration is impaired (Akerman et al. 1992, Cressman et al. 1996). GLP-1 and its analogues can decrease the production of inflammatory cytokines (BenShlomo et al. 2011, Wang et al. 2014). This way GLP-1 could attenuate process of liver regeneration or at least its early DNA-synthesizing phase.

Other potential explanation concerns SIRT1 (silent mating type information regulation 2 homolog 1), an enzyme that contributes to a regulation on many cellular processes, including lipogenesis, protein synthesis and saccharide metabolism (Boutant and Canto 2013). Garcia-Rodriguez et al. (2014) described that transgenic mice overexpressing SIRT1 showed increased mortality, impaired hepatocyte proliferation and profuse liver injury after PHx. On the other hand, Jin et al. showed that (1) levels of SIRT1 are increased in the liver of young mice after PHx, (2) reduced SIRT1 expression correlated with an impaired liver regeneration and (3) normalization of SIRT1 restored the regeneration (Jin et al. 2011). These results suggest that both decreased and increased activity of SIRT1 could attenuate the process of liver regeneration. It was described that Ex4 activates SIRT1 signaling cascade (Lee et al. 2012), thereby
GLP-1 analogues could through this action attenuate the process of liver regeneration.

With respect to a limited amount of information based on the animal experimental model, the results described in the present manuscript suggest that condition of patients' liver should be carefully taken into account prior to an administration of both GLP-1 analogues. Special attention should be paid to patients undergoing liver surgery. However, further experimental studies must be carried out to elucidate the exact meaning of the results described.

In conclusion, our results suggest that GLP-1 analogues, Exenatide and Liraglutide, significantly inhibit the early phase of liver regeneration after partial hepatectomy in rats. Liraglutide effect was more pronounced than that of Exenatide. Based on the present data, this inhibition might be explained by (1) suppressed TAG accumulation in regenerating liver and lower serum TAG concentration forming less favorable energy condition for regenerating hepatocytes and (2) increased utilization of amino acids that could become alternative energy substrates when TAG utilization is disrupted.

\section{Conflict of Interest}

There is no conflict of interest.

\section{Acknowledgements}

This work was supported by grants from Charles University in Prague GAUK 1488213 and Progres Q40/02.

\section{Abbreviations}

ALP - alkaline phosphatase, ALT - alanine aminotransferase, AST - aspartate aminotransferase, B.w. - body weight, BrdU - 5-bromo-2-deoxyuridine, DNA deoxyribonucleic acid, DPP4 - dipeptidyl peptidase 4, Ex4 - exenatide, FFA - free fatty acids, GLP-1 glucagon-like peptide-1, LAP - laparotomy, LIRA liraglutide, PHx - 2/3 partial hepatectomy, S - saline, Sirt1 - silent mating type information regulation 2 homolog 1, TAG - triacylglycerols.

\section{References}

AKERMAN P, COTE P, YANG SQ, MCCLAIN C, NELSON S, BAGBY GJ, DIEHL AM: Antibodies to tumor necrosis factor-alpha inhibit liver regeneration after partial hepatectomy. Am J Physiol 263: G579-G585, 1992.

ALCANTARA AI, MORALES M, DELGADO E, LOPEZ-DELGADO MI, CLEMENTE F, LUQUE MA, MALAISSE WJ, VALVERDE I, VILLANUEVA-PEÑACARRILLO ML: Exendin-4 agonist and exendin (9-39)amide antagonist of the GLP-1 (7-36)amide effects in liver and muscle. Arch Biochem Biophys 341: 1-7, 1997. 
AVIV V, MEIVAR-LEVY I, RACHMUT IH, RUBINEK T, MOR E, FERBER S: Exendin-4 promotes liver cell proliferation and enhances the PDX-1-induced liver to pancreas transdifferentiation process. J Biol Chem 284: 33509-33520, 2009.

BADER A, PAVLICA S, DEIWICK A, LOTKOVÁ H, KUČERA O, DARSOW K, BARTEL S, SCHULZE M, LANGE HA, ČERVINKOVÁ Z: Proteomic analysis to display the effect of low doses of erythropoietin on rat liver regeneration. Life Sci 89: 827-833, 2011.

BAGGIO LL, DRUCKER DJ: Biology of incretins: GLP-1 and GIP. Gastroenterology 132: 2131-2157, 2007.

BAN K, NOYAN-ASHRAF MH, HOEFER J, BOLZ SS, DRUCKER DJ, HUSAIN M: Cardioprotective and vasodilatory actions of glucagon-like peptide 1 receptor are mediated through both glucagon-like peptide 1 receptor-dependent and -independent pathways. Circulation 117: 2340-2350, 2008.

BEN-SHLOMO S, ZVIBEL I, RABINOWICH L, GOLDINER I, SHLOMAI A, SANTO EM, HALPERN Z, FISHMAN S: Dipeptidyl peptidase 4-deficient rats have improved bile secretory function in high fat dietinduced steatosis. Dig Dis Sci 58: 172-178, 2013.

BEN-SHLOMO S, ZVIBEL I, SHNELL M, SHLOMAI A, CHEPURKO E, HALPERN Z, BARZILAI N, OREN R, FISHMAN S: Glucagon-like peptide-1 reduces hepatic lipogenesis via activation of AMP-activated protein kinase. J Hepatol 54: 1214-1223, 2011.

BJERRE KNUDSEN L, MADSEN LW, ANDERSEN S, ALMHOLT K, DE BOER AS, DRUCKER DJ, GOTFREDSEN C, EGEROD FL, HEGELUND AC, JACOBSEN H, ET AL.: Glucagon-like Peptide-1 receptor agonists activate rodent thyroid C-cells causing calcitonin release and C-cell proliferation. Endocrinology 151: 1473-1486, 2010.

BLIGH EG, DYER WJ: A rapid method of total lipid extraction and purification. Can J Biochem Physiol 37: 911-917, 1959.

BOUTANT M, CANTO C: SIRT1 metabolic actions: Integrating recent advances from mouse models. Mol Metab 3: 5-18, 2013.

BRADFORD MM: A rapid and sensitive method for the quantitation of microgram quantities of protein utilizing the principle of protein-dye binding. Anal Biochem 72: 248-254, 1976.

BROSNAN JT: Interorgan amino acid transport and its regulation. J Nutr 133 (Suppl 1): 2068S-2072S, 2003.

BUCHER NL: Regeneration of mammalian liver. Int Rev Cytol 15: 245-300, 1963.

CRESSMAN DE, GREENBAUM LE, DEANGELIS, RA, CILIBERTO G, FURTH EE, POLI V, TAUB R: Liver failure and defective hepatocyte regeneration in interleukin-6-deficient mice. Science 274: 1379-1383, 1996.

DELAHUNTY TJ, RUBINSTEIN D: Accumulation and release of triglycerides by rat liver following partial hepatectomy. J Lipid Res 11: 536-543, 1970.

DING X, SAXENA NK, LIN S, GUPTA NA, ANANIA FA: Exendin-4, a glucagon-like protein-1 receptor agonist, reverses hepatic steatosis in ob/ob mice. Hepatology 43: 173-181, 2006.

EISSELE R, GÖKE R, WILLEMER S, HARTHUS HP, VERMEER H, ARNOLD R, GÖKE B: Glucagon-like peptide-1 cells in the gastrointestinal tract and pancreas of rat, pig and man. Eur J Clin Invest 22: 283-291, 1992.

FABRIKANT JI: The kinetics of cellular proliferation in regenerating liver. J Cell Biol 36: 551-565, 1968.

FARILlA L, HUI H, BERTOLOTTO C, KANG E, BULOTTA A, Di MARIO U, PERFETTI R: Glucagon-like peptide-1 promotes islet cell growth and inhibits apoptosis in Zucker diabetic rats. Endocrinology 143: 4397-4408, 2002.

FAUSTO N, CAMPBELL JS, RIEHLE KJ: Liver regeneration. Hepatology 43 (Suppl 1): S45-S53, 2006.

FELIG P: Amino acid metabolism in man. Annu Rev Biochem 44: 933-955, 1975.

FERNÁNDEZ MA, ALBOR C, INGELMO-TORRES M, NIXON SJ, FERGUSON C, KURZCHALIA T, TEBAR F, ENRICH C, PARTON RG, POL A: Caveolin-1 is essential for liver regeneration. Science 313: 1628-1632, 2006.

GARCIA-RODRIGUEZ JL，BARBIER-TORRES L， FERNANDEZ-ALVAREZ S， GUTIÉRREZ-DE JUAN V, MONTE MJ, HALILBASIC E, HERRANZ D, ALVAREZ L, ASPICHUETA P, MARÍN JJ, ET AL.: SIRT1 controls liver regeneration by regulating bile acid metabolism through farnesoid $\mathrm{X}$ receptor and mammalian target of rapamycin signaling. Hepatology 59: 1972-1983, 2014. 
GRISHAM JW: A morphologic study of deoxyribonucleic acid synthesis and cell proliferation in regenerating rat liver; autoradiography with thymidine-H3. Cancer Res 22: 842-849, 1962.

HANSE EA, NELSEN CJ, GOGGIN MM, ANTTILA CK, MULLANY LK, BERTHET C, KALDIS P, CRARY GS, KURIYAMA R, ALBRECHT JH: Cdk2 plays a critical role in hepatocyte cell cycle progression and survival in the setting of cyclin D1 expression in vivo. Cell Cycle 8: 2802-2809, 2009.

HIGGINS GM, ANDERSON RM: Experimental pathology of the liver I. Restoration of the liver of the white rat following partial surgical removal. Arch Pathol 12: 186-202, 1931.

HOLEČEK M: Nutritional modulation of liver regeneration by carbohydrates, lipids, and amino acids: a review. Nutrition 15: 784-788, 1999.

HOLST JJ: The physiology of glucagon-like peptide 1. Physiol Rev 87: 1409-1439, 2007.

JIN J, IAKOVA P, JIANG Y, MEDRANO EE, TIMCHENKO NA: The reduction of SIRT1 in livers of old mice leads to impaired body homeostasis and to inhibition of liver proliferation. Hepatology 54: 989-998, 2011.

KAIBORI M, KWON AH, NAKAGAWA M, WEI T, UETSUJI S, KAMIYAMA Y, OKUMURA T, KITAMURA N: Stimulation of liver regeneration and function after partial hepatectomy in cirrhotic rats by continuous infusion of recombinant human hepatocyte growth factor. J Hepatol 27: 381-390, 1997.

KAR S, WANG M, ROSI KS, WILCOX CS, CARR BI: Inhibition of rat liver regeneration after partial hepatectomy and induction of ERK phosphorylation by $\mathrm{Cpd} \mathrm{5,} \mathrm{a} \mathrm{K} \mathrm{vitamin-based} \mathrm{anticancer} \mathrm{compound.} \mathrm{Carcinogenesis} \mathrm{25:}$ 2345-2351, 2004.

KOEHLER JA, BAGGIO LL, LAMONT BJ, ALI S, DRUCKER DJ: Glucagon-like peptide-1 receptor activation modulates pancreatitis-associated gene expression but does not modify the susceptibility to experimental pancreatitis in mice. Diabetes 58: 2148-2161, 2009.

LEE J, HONG SW, CHAE SW, KIM DH, CHOI JH, BAE JC, PARK SE, RHEE EJ, PARK CY, OH KW, ET AL.: Exendin-4 improves steatohepatitis by increasing Sirt1 expression in high-fat diet-induced obese C57BL/6J mice. PLoS One 7: e31394, 2012.

MAYO KE, MILLER LJ, BATAILLE D, DALLE S, GÖKE B, THORENS B, DRUCKER DJ: International Union of Pharmacology. XXXV. The glucagon receptor family. Pharmacol Rev 55: 167-194, 2003.

MELLS JE, FU PP, SHARMA S, OLSON D, CHENG L, HANDY JA, SAXENA NK, SORESCU D, ANANIA FA: Glp-1 analog, liraglutide, ameliorates hepatic steatosis and cardiac hypertrophy in C57BL/6J mice fed a Western diet. Am J Physiol Gastrointest Liver Physiol 302: G225-G235, 2012.

MICHALOPOULOS GK: Liver regeneration. J Cell Physiol 213: 286-300, 2007.

NAUCK MA, HOMBERGER E, SIEGEL EG, ALLEN RC, EATON RP, EBERT R, CREUTZFELDT W: Incretin effects of increasing glucose loads in man calculated from venous insulin and C-peptide responses. $J$ Clin Endocrinol Metab 63: 492-498, 1986.

PATEL KN, JOHARAPURKAR AA, PATEL V, KSHIRSAGAR SG, BAHEKAR R, SRIVASTAVA BK, JAIN MR: Cannabinoid receptor 1 antagonist treatment induces glucagon release and shows an additive therapeutic effect with GLP-1 agonist in diet-induced obese mice. Can J Physiol Pharmacol 92: 975-983, 2014.

RIGOTTI P, PETERS JC, TRANBERG KG, FISCHER JE: Effects of amino acid infusions on liver regeneration after partial hepatectomy in the rat. JPEN J Parenter Enteral Nutr 10: 17-20, 1986.

RUDNICK DA, DAVIDSON NO: Functional relationships between lipid metabolism and liver regeneration. Int J Hepatol 2012: 549241, 2012.

RUSSEL-JONES D, GOUGH S: Recent advances in incretin-based therapies. Clin Endocrinol (Oxf) 77: 489-499, 2012.

SAMSON SL, BAJAJ M: Potential of incretin-based therapies for non-alcoholic fatty liver disease. $J$ Diabetes Complications 27: 401-406, 2013.

SCHOFIELD PS, SUGDEN MC, CORSTORPHINE CG, ZAMMIT VA: Altered interactions between lipogenesis and fatty acid oxidation in regenerating rat liver. Biochem $J$ 241: 469-474, 1987.

SEKAS G, COOK RT: The evaluation of liver function after partial hepatectomy in the rat: serum changes. Br $J$ Exp Pathol 60: 447-452, 1979.

SHARMA S, MELLS JE, FU PP, SAXENA NK, ANANIA FA: GLP-1 analogs reduce hepatocyte steatosis and improve survival by enhancing the unfolded protein response and promoting macroautophagy. PLoS One 6 : e25269, 2011. 
SHTEYER E, LIAO Y, MUGLIA LJ, HRUZ PW, RUDNICK DA: Disruption of hepatic adipogenesis is associated with impaired liver regeneration in mice. Hepatology 40: 1322-1332, 2004.

ŠIMEK J, SEDLÁČEK J: Effect of glucose administered in vivo or in vitro on the respiratory quotient of rat liver tissue after partial hepatectomy. Nature 207: 761-762, 1965.

TANAKA R, TAINAKA M, OTA T, MIZUGUCHI N, KATO H, URABE S, CHEN Y, FUSTIN JM, YAMAGUCHI Y, DOI M, ET AL.: Accurate determination of S-phase fraction in proliferative cells by dual fluorescence and peroxidase immunohistochemistry with 5-bromo-2'-deoxyuridine (BrdU) and Ki67 antibodies. $J$ Histochem Cytochem 59: 791-798, 2011.

TIJBURG LB, NYATHI CB, MEIJER GW, GEELEN MJ: Biosynthesis and secretion of triacylglycerol in rat liver after partial hepatectomy. Biochem J 277: 723-728, 1991.

TOMAS E, HABENER JF: Insulin-like actions of glucagon-like peptide-1: A dual receptor hypothesis. Trends Endocrinol Metab 21: 59-67, 2010.

VILSBOLL T, AGERSO H, KRARUP T, HOLST JJ: Similar elimination rates of glucagon-like peptide-1 in obese type 2 diabetic patients and healthy subjects. J Clin Endocrinol Metab 88: 220-224, 2003.

VRANG N, JELSING J, SIMONSEN L, JENSEN AE, THORUP I, SØEBORG H, KNUDSEN LB: The effects of $13 \mathrm{wk}$ of liraglutide treatment on endocrine and exocrine pancreas in male and female ZDF rats: a quantitative and qualitative analysis revealing no evidence of drug-induced pancreatitis. Am J Physiol Endocrinol Metab 303: E253-E264, 2012.

WANG Y, PARLEVLIET ET, GEERLING JJ, VAN DER TUIN SJ, ZHANG H, BIEGHS V, JAWAD AH, SHIRISVERDLOV R, BOT I, DE JAGER SC, ET AL.: Exendin-4 decreases liver inflammation and atherosclerosis development simultaneously by reducing macrophage infiltration. Br J Pharmacol 171: 723-734, 2014.

WEINBREN K, TAGHIZADEH A: The mitotic response after subtotal hepatectomy in the rat. Br J Exp Pathol 46: 413-417, 1965. 